loét trên người bệnh mổ chấn thương cột sống thắt lưng và có liêt tủy tai khoa Chấn thương chỉnh hình bệnh viện Việt Đức", Khóa luận TN, Trường ĐHY Hă Nôi.

3. Lê Thị Trang, Pham Thị Kim Thoa, Hoàng Gia Du, Vũ Xuấn Phước, Nguyễn Đức Hoàng (2019),"Thực trạng loét tỳ đè trên bênh nhân chấn thương cột sống có liệt tủy tại khoa chấn thương chỉnh hình và cột sống Bênh viện Bach Mai", Tap chí y học việt nam, 2(484), tr. 244-249.

4. Phan Thi Dung (2017), "Nhâan xét phòng loét tỳ đè của điều dưỡng qua trường hợp nghiên cứu tai Bệnh viện hữu nghị Việt Đức", Tạp chí y học thảm họa và bỏng, 3(12), tr.56-59.

5. Trân Hồng Huệ, Nguyễn Thị Lan Minh
(2016), "Khảo sát loét tỳ đè ở bệnh nhân tại các phòng bệnh nặng trong bệnh viện Nguyển Tri Phương", Tạp chí y học TP Hồ Chí Minh, 3(21), tr.112-116.

6. Trân Văn Oánh, Nguyễn Thì Hằng, Chu Văn Long, Nguyễn Ngọc Thực, Nguyển Hữu Trung, Pham Thị Sơn và cộng sự (2016), "Giải pháp dự phòng loét tỳ đè trên người bệnh tại phòng hî̀i sức khoa nội- hồi sức thần kinh Bệnh viên Hà Nôi Viêtt Đức", tr 29-35.

7. Vứ Thị Kìm Định, Đào Quang Minh (2019)," Khảo sát nquy cơ loét tỳ đè và các yêu tố liến quan trên bênh nhân nội trú tại khoa hồi sức tích cực Bệnh viện Thanh Nhàn", Tạp chí y học cộng đồng", 3(50), tr.134-139.

\title{
HÌNH THÁI ỐNG TỦY RĂNG SỐ 7 HÀM TRÊN CỦA NGƯỜI HÀ NộI
}

\section{Pham Như Hải*, Trương Thi Mai Anh*, Nguyễn Văn Giang*, Nguyễn Thị Như Trang*}

\section{TÓM TẮT}

Chụp cắt lớp vi tính chùm tia hình nón $(\mathrm{CBCT})$ là một công cụ có giá trị cho điều trị nội nha. Mục đích của nghiên cứu này là xác định hình thái của ổng tủy răng hàm 7 hàm trên. CBCTं của 360 bệnh nhân đã được sử dụng. Kết quả như sau: Số lượng chân răng 4 $(0,4 \%), 3(91,25 \%), 2(6,94 \%), 1$ (1,4\%). 84,7\% răng chân gân ngoài chỉ có 1 ống tủy, nữ $(85,5 \%)$ cao hơn nam $(83,8 \%)$. Sự khác nhau bên phải và trái không có ý nghĩa thống kê. Chân xa và chân trong chì có 1 ống tủy từ lỗ vào ống tủy đến chóp răng. Hình thái ống tủy chữ $C$ chiếm $20,8 \%$, trong đó hình thái $B 1$ chiếm $8,9 \%$ và $A$ chiếm 7,6\%. Không khác biêt 2 bên phải trái, nhưng hay gặp ở nữ $(24,3 \%)$ hơn là ở nam $(16,6 \%)$

Tứ khóa: ống tủy, nội nha, cone-beam, răng 7 hàm trên.

\section{SUMMARY}

\section{ROOT CANAL MORPHOLOGY AND} CONFIGURATION MAXILARY SECOND MOLARS

Cone-beam computed tomographic (CBCT) imaging is a valuable tool for endodontic therapy. The aim of this study was to identify morphology of second upper molar root canal . CBCT of 360 patients were used. Results were as follows: Number of roots 4 $(0.4 \%), 3(91.25 \%), 2$ (6.94\%), 1 (1.4\%). 84.7\% of the mesio-bucal root teeth have only 1 root canal, women $(85.5 \%)$ higher than men $(83.8 \%)$, no difference on the right and left side. The distal and medial roots have only one canal from the canal entrance to the apex. The morphology of the C-

*Trường Đai hoc Y Dước-Đai hoc Quốc Gia Hà Nôi Chịu trách nhiệm chính: Phạm Như Hải

Email: phamnhuhai@yahoo.com

Ngày nhận bài: 15.3.2021

Ngày phản biên khoa hoc: 10.5.2021

Ngày duyệt bài: 20.5.2021 shaped canal accounts for $20.8 \%$, of which the B1 form accounts for $8.9 \%$ and $A$ accounts for $7.6 \%$. No difference between right and left, but more common in women $(24.3 \%)$ than in men $(16.6 \%)$.

Key words; root canal, endodontic, cone-beam computed tomographic,

\section{I. ĐĂT VẤN ĐỀ}

Chuyên nghiệp hóa trong lĩnh vực hình thái hoc tủy răng là rất quan trọng để thành công điêuu trị nội nha. Để tránh thất bại nội nha, đặc biệt trong quá trình chuẩn bị và hàn kín ống tủy, bác sĩ phải có kiến thức rộng về hình thái chân răng. Do mỗi răng đều có đăcc điểm riêng, nêu tạo ra một số lượng lớn các biến thể về số lượng và hình thái ống tủy. Những đặc điểm như vậy làm khó khăn trong việc tạo hình, làm sạch và trám bít hệ thống ống tủy ba theo 3 chiêu không gian. Thực hiện những yêu câu như vậy là cơ bản để điêuu trị nội nha thành công, và để bảo tồn lâu dài răng.

Mă̆t khác, sự hiểu biết không chính xác về tính phức tạp của hình thái ống tủy luôn dẫn đến không có phương pháp và cách thức tạo hình ống tủy phù hợp. Các thông số giải phẫu thường được mô tả trong tài liệu là răng hàm trên thứ hai có 3 chân răng và 3 ống tủy mà không nêu ra được các biến thể có thể gặp cũng như tỷ lệ để các bác sĩ lâm sàng cẩn trọng khi điều trị tủy cho bênh nhân.

Hiện nay, những tiến bộ công nghệ trong chụp phim răng trên lâm sàng đã cho phép thu được hình ảnh theo 3 chiêu không gian, cho phép mô tả chính xác, bao quát và toàn diện về hình thái răng; 


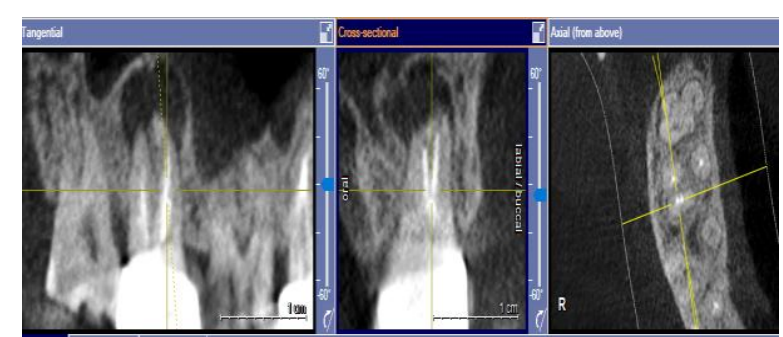

Hình 1: trường hợp chân gần răng 17 có 2 ống tủy

Mỗi chủng tộc lại có cấu tạo giải phẫu răng khác nhau, thậm chí đặc điểm vùng miền cũng có thể góp phần tạo sự khác biệt về hình thái và giải phẩu[1,2]. Do đó cho phép người thực hành có những dữ liệu tham khảo về hệ thống ống tủy răng 7 hàm trển ở người miền bắc chúng tôi đã tiến hành nghiên cứu này với mục tiêu:

1. Xác định số lượng và hình thái ống tủy của răng 7 hàm trên bằng phim Conebeam ở người khu vực Hà Nội và lân cận.

2. Tìm mối tương quan giữa giới tính và hình thái cảu răng 7 hàm trên

\section{II. ĐỐI TƯợNG VÀ PHƯƠNG PHÁP NGHIÊN CỨU}

2.1 . Đối tượng: Mẫu nghiên cứu gồm 360 răng cối II hàm trên phải và trái của 360 phim conebeam CT của bệnh nhân Hà Nội và vùng lân cận, gồm 160 nam và 200 nữ, tuổi từ 18 đến

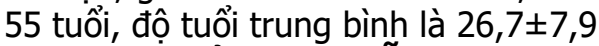

Tiêu chuẩn chon mẫu:

- Có đủ 2 răng số 7 hàm trên

- Các răng số 7 hàm trên có chân răng phát triển hoàn toàn

- Hình ảnh conebeam CT rõ ràng, thể hiện được hình ảnh các ống tủy.

Tiêu chuẩn loại trữ: Các răng số 7 hàm trên đã bị

- Tiêu ngót chân rang

- Trám bít hoặc có miếng trám đến tủy

- Phục hồi kim loại như chốt, mão

- Nghiêng hoặc mọc ngầm

Cỡ mẫu. Răng cối lớn thứ nhất hàm trên: dựa vào kết quả nghiên cứu của Wolf1 Thomas Gerhard (2017), tỉ lệ chân gần ngoài răng cối lớn thứ nhất hàm trên có $\geq 2$ ống tủy là $68 \%$ [3]. Áp dụng vào công tức tính cõ mẫu:

Độ tin cậy 95\%, Z (1- a/2) =1,96; d=0,05 Cõ mẫu tối thiểu là 334 răng

$$
\mathrm{n}=\frac{\mathrm{Z}_{1-\alpha / 2}^{2} \mathrm{P}(1-\mathrm{P})}{\mathrm{d}^{2}}
$$

2.2. Phương pháp nghiên cứu: Nghiên cứu thực hiện theo thiết kế cắt ngang mô tả phân tích trên conebeam CT. Bệnh nhân này đã được chụp conebeam CT bằng máy Galileos
(Sirona Dental System Inc., Đức), kích cõ voxel $0,3 \mathrm{~mm} \times 0,3 \mathrm{~mm} \times 0,3 \mathrm{~mm}$, Gray scale 12 bit tại bộ môn Răng Hàm Mặt, Đại học Y dược, Đại Học Quốc Gia Hà Nội và phòng chụp Xquang Hà Thành trong khoảng thời gian từ tháng 6 năm 2019 đến tháng 4 năm 2021.

Quan sát hình ảnh bằng phần mềm Galileos Viewer (Sirona Dental System Inc.) trên màn hình 24 inch có độ phân giải $1.920 \times 1.200$, độ tương phản $1.000: 1$, bề dày mỗi lát cắt $1 \mathrm{~mm}$. Trình tự thực hiện như sau:

Đầu tiên, điều chỉnh lát cắt trên cửa sổ Tangential đi qua đúng giữa trục chân răng của từng chân răng hàm lớn II cần đo. Sau đấy, điêu chỉnh mặt phẳng cắt trên cửa sổ Cross-sectional theo đúng trục của răng hàm được đo. Di chuyển lát cắt trên cửa sổ Axial để kiểm tra số lượng và hình thái ống tủy của mỗi chân răng (hình 2).

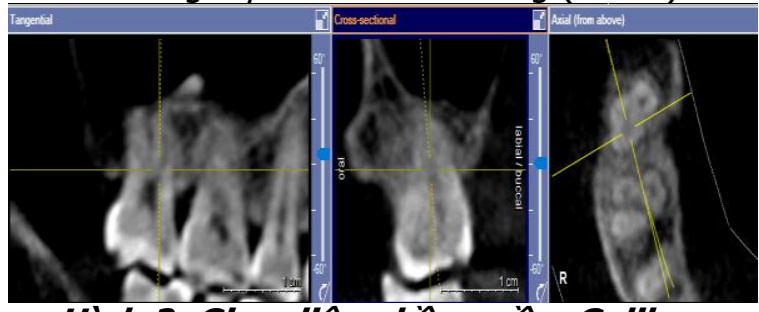

Hình 2: Giao diện phầm mềm Gelileos Viewer, điều chỉnh đê quan sát chân gân ngoài răng cối lớn II hàm trên, bên phải. Chân này có ống tủy, loại I theo Vertucci

Điều tra viên chính khảo sát hình ảnh conebeam CT của từng bệnh nhân để chọn bệnh nhân và chọn răng thỏa tiêu chuẩn chọn mẫu. Bệnh nhân và răng được chọn được ghi nhận dữ liệu chung và dữ liệu về hình thái chân răng và ống tủy. Quan sát từng răng, từng chân răng, đo ở 2 thời điểm khác nhau, nếu số liệu khác nhau thì sẽ nhờ người thứ 2 kiêm tra.

Hình thái ống tủy: được ghi nhận theo phân loại Vertucci (1984)[4,5]. Nhứng ống tủy có hình thái khác ngoài phân loại Vertucci được ghi nhận theo số ống tủy thay đổi theo chiều dài chẩn răng từ cổ đến chóp.
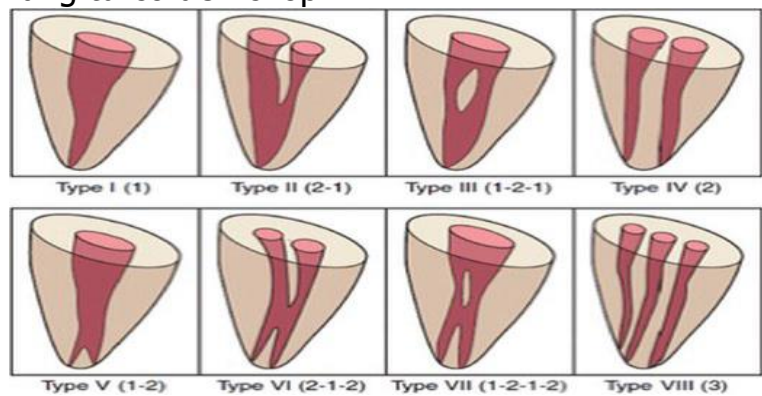

Hình 3: Phân loại hình thái ống tủy theo Vertucci 
Nguồn:https://www.intechopen.com/books/h uman-teeth-key-skills-and-clinical-

illustrations/morphology-of-root-canal-system-ofmaxillary-and-mandibular-molars

Hình thái ống tủy: ghi nhận theo phân loại Vertucci (1984) gồm 8 loại (hình 3):

Loại I: chỉ có một ống tủy từ buồng tủy đến lỗ chóp chân răng.

Loại II: có hai ống tủy xuất phát từ buồng tủy tạo thành hai ống tủy riêng biệt nhưng gặp nhau ở gần chóp để thành một ống tủy và ra khỏi chân răng bằng một lỗ chóp.

Loại III: có một ống tủy xuất phát từ buồng tủy nhưng sau đó chia hai và gặp nhau ở gần chóp để tạo một ống tủy và ra khỏi chân răng bằng một î̃ chóp.

Loại IV: có hai ống tủy riêng biệt kéo dài từ buồng tủy tới chóp chân răng.

Loại V: một ống tủy xuất phát từ buồng tủy, sau đó tách ra thành hai ống tủy và đi khỏi chân răng bằng hai lỗ chóp riêng biệt.

Loại VI: hai ống tủy xuất phát từ buồng tủy, kết hợp lại thành một ống tủy và sau đó lại chia hai ở chóp với hai Iỗ chóp riêng biêt.

Loại VII: một ống tủy xuất phát từ buồng tủy, chia hai sau đó kết hợp lại thành một ống tủy và lại chia hai ở chóp với hai lỗ chóp riểng biệt.

Loại VIII: có ba ống tủy riêng biệt kéo dài từ buồng tủy đến chóp chân răng.
Ống tủy hình C: khi các ống tủy hợp lại với nhau tạo thành 1 ống tủy dạng dải cong, hình chữ $C$. Ống tủy hình $C$ được quan sát trong thiết diện cắt ngang để ghi nhận hình thái và số lượng ống tủy ở từng phần ba chân răng: phần ba cổ, phần ba giữa và phần ba chóp. Ông tủy hình $C$ được ghi nhận theo phân loại của Martin (2016) [6](hình 4 và 5 ).

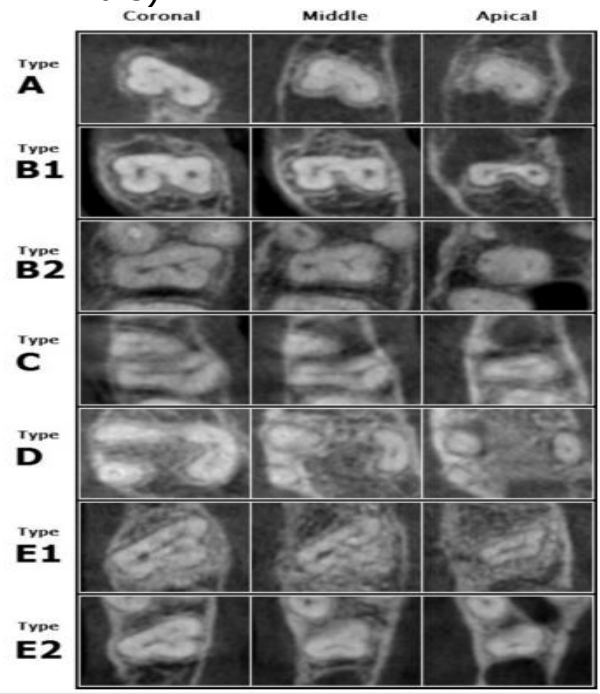

Hình 5: phân loại theo Martin đọc trên phim conebeam

Phương pháp xử lý số liệu: xử lý số liệu bằng phần mềm thống kê R4.0.5.

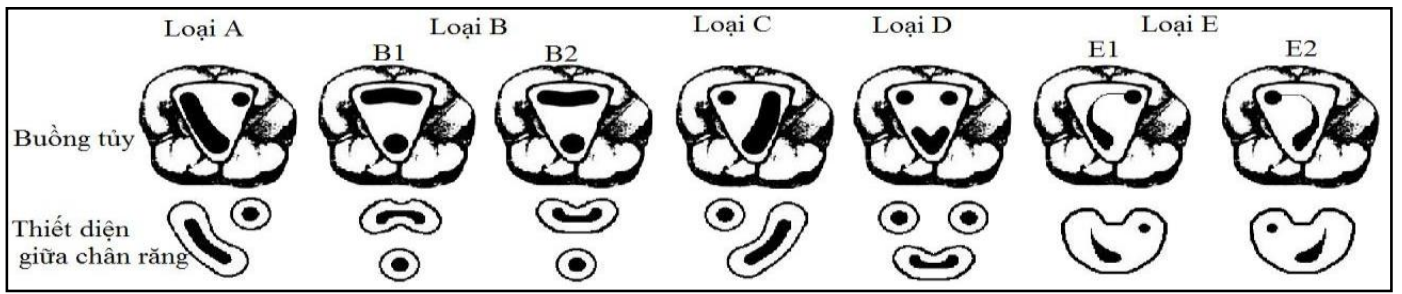

Hình 4: Phân loại ống tủy hình C ở răng côi lớn hàm trên dựa vào vị trí các ống tủy "Nguồn: Martins, 2016".

\section{KẾT QUẢ NGHIÊN CỨU}

3.1. Xác định số lượng và hình thái ống tủy của răng 7 hàm trên bằng phim Conebeam ở người khu vực Hà Nội và lân cận.

\subsubsection{Sốlường chân răng 7 hàm trên}

Bảng 1: Số lượng chân răng 7 hàm trên

\begin{tabular}{|c|c|c|c|c|c|}
\hline Số lượng chân & Răng 17 & Răng 27 & P & Tống & Tỷ lệ \\
\hline 1 chân & 5 & 5 & 1 & 10 & $1.4 \%$ \\
\hline 2 chân & 25 & 25 & 1 & 50 & $6.9 \%$ \\
\hline 3 chân & 329 & 328 & 1 & 657 & $91.3 \%$ \\
\hline 4 chân & 1 & 2 & 1 & 3 & $0.4 \%$ \\
\hline Tống & $\mathbf{3 6 0}$ & $\mathbf{3 6 0}$ & & $\mathbf{7 2 0}$ & \\
\hline
\end{tabular}

Số lượng chân răng 2 bên phải và trái khác biệt nhau không có ý nghĩa thống kê. Chủ yếu là 3 chân răng chiếm $91,25 \%$, sau đây là răng 2 chân $(6,94 \%), 1$ chân $(1,4 \%)$ và 4 chân $(0,4 \%)$ rất ít gặp.

\subsubsection{Hình thái ông tủy chân gần ngoài của răng 7 theo Vertucci}


Bảng 2: Hình thái ống tủy chân gần ngoài của răng 7 theo Vertucci

\begin{tabular}{|c|c|c|c|c|c|}
\hline Hình thái ống tủy & Răng 17 & Răng 27 & P & Tống & Tỷ lệ \\
\hline Loại I theo Vertucci & 302 & 308 & 0,60 & 610 & $84.7 \%$ \\
\hline Loại II theo Vertucci & 33 & 24 & 0,27 & 57 & $7.9 \%$ \\
\hline Loại III theo Vertucci & 1 & 4 & 0,37 & 5 & $0.7 \%$ \\
\hline Loại IV theo Vertucci & 16 & 18 & 0,86 & 34 & $4.7 \%$ \\
\hline Loại V theo Vertucci & 7 & 5 & 0,77 & 12 & $1.7 \%$ \\
\hline Loại VI theo Vertucci & 1 & 1 & 1 & 2 & $0.3 \%$ \\
\hline Loại VII theo Vertucci & 0 & 0 & & 0 & \\
\hline Loại VIII theo Vertucci & 0 & 0 & & 0 & \\
\hline & 360 & 360 & & 720 & \\
\hline
\end{tabular}

Chân gần ngoài răng 7 trên chủ yếu có 1 ông tủy thằng từ trên xuống (vertucci I) chiếm 84,7\%. Sự khác nhau bên phải và trái không có ý nghĩa thống kê. Chân xa và chân trong chỉ có 1 ống tủy từ lố vào ống tủy đến chóp răng (loai I Vertucci)

\subsubsection{Hình thái ống tủy hình chữ $C$ răng 7}

Bảng 3: Hình thái ông tủy hình chữ C răng 7

\begin{tabular}{|c|c|c|c|c|c|}
\hline Hình thái & Răng 17 & Răng 27 & P & Tống & Tỷ lệ \\
\hline A & 32 & 23 & 0,46 & 55 & $7.6 \%$ \\
\hline B1 & 34 & 30 & 1 & 64 & $8.9 \%$ \\
\hline B2 & 5 & 5 & 1 & 10 & $1.4 \%$ \\
\hline D & 3 & 3 & 1 & 6 & $0.8 \%$ \\
\hline E1 & 0 & 0 & 0 & 0 & $0.0 \%$ \\
\hline E2 & 5 & 9 & 0,27 & 14 & $1.9 \%$ \\
\hline & 1 & 0 & 1 & 1 & $0.1 \%$ \\
\hline
\end{tabular}

Trong số 720 răng 7 hàm trên 2 bên thì có 80 răng 17 và 70 răng 27 có hình thái ống tủy chữ $C$ chiếm $20,8 \%$, trong đó hình thái $B 1(8,9 \%)$ và $A(7,6 \%)$ chiếm tỷ lệ cao nhất. sự khác biệt về hình thái 2 bên không có ý nghĩa thống kê

3.2 Mối liên quan giới tính với hình thái chân răng 7 hàm trên

\subsubsection{Số lương chẩn răng 7 hàm trên}

Bảng 4 Mối liến quan giữa giới tính với số lượng chân răng

\begin{tabular}{|c|c|c|c|c|c|}
\hline Số lượng chân răng & Nam & Tỷ lệ & Nữ & Tỷ lệ & P \\
\hline 1 chân & 2 & $0.6 \%$ & 8 & $2.0 \%$ & 0,21 \\
\hline 2 chân & 13 & $4.1 \%$ & 37 & $9.3 \%$ & 0,01 \\
\hline 3 chân & 303 & $94.7 \%$ & 354 & $88.5 \%$ & 0,005 \\
\hline 4 chân & 2 & $0.6 \%$ & 1 & $0.3 \%$ & 0,84 \\
\hline Tống & $\mathbf{3 2 0}$ & & $\mathbf{4 0 0}$ & & \\
\hline
\end{tabular}

Số lượng răng 7 trên có 3 chân ở nam $(94,7 \%)$ nhiêu hơn nữ $(88,5 \%)$ nhưng số lượng răng 7 hàm trên ở nữ có 2 chân $(9,3 \%)$ lại nhiêu hơn nam $(4,1 \%)$, khác biệt có ý nghĩa thống kể. Số lượng chân răng 1 và 4 chân khác biệt không có ý nghĩa thống kê

\subsubsection{Hình thái chân răng gần ngoài theo Vertucci}

Bảng 5: Môí liên quan giữa giới tính với hình thái chân răng gần ngoài

\begin{tabular}{|c|c|c|c|c|c|}
\hline Hình thái chân răng & Nam & Tỷ lệ & Nữ & Tỷ lệ & P \\
\hline Loại I theo Vertucci & 268 & $83.8 \%$ & 342 & $85.5 \%$ & $1,6 \times 10^{-11}$ \\
\hline Loại II theo Vertucci & 28 & $8.8 \%$ & 29 & $7.3 \%$ & 0,54 \\
\hline Loại III theo Vertucci & 2 & $0.6 \%$ & 3 & $0.8 \%$ & 1 \\
\hline Loại IV theo Vertucci & 14 & $4.4 \%$ & 20 & $5.0 \%$ & 0,83 \\
\hline Loại V theo Vertucci & 6 & $1.9 \%$ & 6 & $1.5 \%$ & 0,92 \\
\hline Loại VI theo Vertucci & 2 & $0.6 \%$ & 0 & $0.0 \%$ & 0,38 \\
\hline Loại VII theo Vertucci & 0 & $0.0 \%$ & 0 & $0.0 \%$ & \\
\hline Loại VIII theo Vertucci & 0 & $0.0 \%$ & 0 & $0.0 \%$ & \\
\hline & 320 & & 400 & & \\
\hline
\end{tabular}

Hình thái chân ngoài gần theo Vertucci I ở nữ là 85,5\% cao hơn ở nam $(83,8 \%)$. Các hình thái khác không có sự khác biệt giữa nam và nữ

\subsubsection{Hình thái ống tủy hình chữ $\mathrm{C}$ răng 7}


VIETNAM MEDICAL JOURNAL N01 - JUNE - 2021

Bảng 6: Môi liên quan giữa giới tính với hình thái ống tủy chữ C

\begin{tabular}{|c|c|c|c|c|c|}
\hline Hình thái & Nam & Tỷ lệ & Nữ & Tỷ lệ & P \\
\hline A & 26 & $49.1 \%$ & 29 & $29.9 \%$ & 0,031 \\
\hline B1 & 23 & $43.4 \%$ & 41 & $42.3 \%$ & 0,031 \\
\hline B2 & 1 & $1.9 \%$ & 9 & $9.3 \%$ & 0,16 \\
\hline D & 1 & $1.9 \%$ & 5 & $5.2 \%$ & 0,59 \\
\hline E1 & 0 & $0.0 \%$ & 0 & $0.0 \%$ & 1 \\
\hline E2 & 2 & $3.8 \%$ & 12 & $12.4 \%$ & 0,15 \\
\hline Tống số răng có hình chữ C & 0 & $0.0 \%$ & 1 & $1.0 \%$ & 1 \\
\hline Tống số răng theo giới & 53 & $16,6 \%$ & 97 & $24,3 \%$ & 0,015 \\
\hline
\end{tabular}

Hình thái ống tủy $C$ hay gặp ở nữ $(24,3 \%)$ hơn nam (16,6\%). Loại $A$ và $B 1$ gặp ở nam nhiêu hơn nữ, khác biệt có ý nghĩa thống kê

\section{BÀN LUÂ̂N}

Trong số 720 răng 7 hàm trên nghiên cứu thì chúng tồi nhận thấy chủ yếu là 3 chân răng chiếm $91,25 \%$, sau đây là răng 2 chân $(6,94 \%)$, 1 chân $(1,4 \%)$ và 4 chân $(0,4 \%)$ rất ít gặp. Số lượng chân răng 2 bên phải và trái khác biệt nhau không có ý nghĩa thống kê. So với nghiên cứu của Huỳnh Hữu Thục Hiền năm 2019 [7] trên 778 răng 7 hàm trên ở người miền nam thì $94,9 \%$ có 3 chân, $3,7 \%$ có 2 chân, $0,9 \%$ có 1 chân, và $0,5 \%$ có 4 chân. Như vậy số răng 7 hàm trên có 3 chân của chúng tôi ít hơn của Huỳnh Hữu Thục Hiền, khác biệt có ý nghĩa thống kê với $p=0,008$, nhưng lớn hớn nhiều so với nghiên cứu của J. Dhayanithi (Bảng 7) ở các chủng tộc khác [8] (dao động từ 15,5\% đến 64,67\%),

Bảng 7: So sánh số lượng chân răng

\begin{tabular}{|c|c|c|c|c|c|c|c|}
\hline Tác giả & Đối tượng & Cỡ mâu & 1 chân & 2 chân & 3 chân & 4 chân & 5 chân \\
\hline Jha, Nikhil, 2012 & CBCT & 500 & $5 \%$ & $20 \%$ & $62 \%$ & $11.4 \%$ & $1.4 \%$ \\
\hline Zmener, Peirano, 1998 & Răng nhố & 549 & $12.02 \%$ & $20.04 \%$ & $64.67 \%$ & $1.28 \%$ & $2 \%$ \\
\hline $\begin{array}{c}\text { Peikoff, Christie, Fogel, } \\
1996\end{array}$ & CBCT & 677 & $15.81 \%$ & $20.34 \%$ & $60.12 \%$ & $0.74 \%$ & $3.34 \%$ \\
\hline Sakamuri, Mallineni, 2018 & CBCT & 10226 & $11.11 \%$ & $21.86 \%$ & $63.05 \%$ & $0.98 \%$ & $3 \%$ \\
\hline Vida e tal,2020 & Micro-CT & 375 & $82.9 \%$ & $82.9 \%$ & $15.5 \%$ & $1.6 \%$ & - \\
\hline Graber,1969; Paul, 2013) & CBCT & 425 & $26.5 \%$ & $73.5 \%$ & - & - & - \\
\hline
\end{tabular}

Về hình thái ống tủy chân răng trong nghiên cứu của chúng tôi thì các chân răng chỉ có 1 ống tủy riêng ống ngoài gần thì các biến thể khác (vertucci 2-6) có thể đến 15,3\% ít hơn nhiều nếu so với nghiên cứu của J. Dhayanithi và CS [8] có đến 40-45\% ống ngoài gần của các răng nghiên cứu có 2 ống tủy (Bảng 8), hay của Mandana Naseri ở người Iran [2] với 67,5\% là Loại II -VI Vertucci. Điều này có thể do đặc điểm giải phẫu của người Việt Nam.

Bảng 8: Hình thái ống tủy ngoài gân răng 7 trên theo Vertucci

\begin{tabular}{|c|c|c|c|c|c|c|c|c|c|c|}
\hline Tác Giả & Đối tượng & $\begin{array}{c}\text { Cỡ } \\
\text { mấu }\end{array}$ & I & II & III & IV & V & VI & VII & VIII \\
\hline $\begin{array}{c}\text { Ahuja, Ballal,and } \\
\text { Velmurugan, 2012 }\end{array}$ & Răng nhổ & 535 & $42.6 \%$ & $47.1 \%$ & - & $8.03 \%$ & $1.87 \%$ & $0.93 \%$ & - & - \\
\hline $\begin{array}{c}\text { Sakamuri and } \\
\text { Mallineni, 2018 }\end{array}$ & Răng nhổ & 36 & $41.6 \%$ & $5.5 \%$ & $4.7 \%$ & $19.4 \%$ & $15.6 \%$ & $13.8 \%$ & - & - \\
\hline $\begin{array}{c}\text { Şımşek, Keleş and } \\
\text { Bulut, 2013 }\end{array}$ & Răng nhổ & 38 & $78.95 \%$ & $13.16 \%$ & $5.56 \%$ & $4.63 \%$ & - & - & - & - \\
\hline Case Report, 2016 & CBCT & 77 & $71.43 \%$ & $14.29 \%$ & $2.60 \%$ & $3.90 \%$ & $7.78 \%$ & - & - & - \\
\hline Jeevanandan, 2017 & Răng nhổ & 644 & $63.48 \%$ & $16.06 \%$ & $0.30 \%$ & $15.1 \%$ & $2.4 \%$ & $0.15 \%$ & - & - \\
\hline Walsh and Smith, 1980 & CBCT & 802 & $36.41 \%$ & $20.45 \%$ & $0.25 \%$ & $40.6 \%$ & $2 \%$ & $0.12 \%$ & - & - \\
\hline
\end{tabular}

Hình thái ống tủy chữ $C$ trong nghiên cứu của chúng tôi chiếm $20,8 \%$, lớn hơn nhiêu nghiên cứu của Martins ] [6] ở người Bồ đào nha trên phim conebeam chỉ có 3,8\% trong tổng số 1299 răng, với các loại hình thái chữ $C$ theo Bảng 9 , trong đấy chiếm nhiều nhất là loại $B 1$ tương tự như nghiên cứu của chúng tôi. Và biến thể chữ $C$ cũng hay gặp ở nữ hơn nam 
Bảng 9: So sánh tỷ lê \% ống tủy chữ C ở răng 7 hàm trên của Martins

\begin{tabular}{|c|c|c|c|c|c|c|c|c|c|c|}
\hline Của Martins J & Không có & Loại A & Loại B1 & Loại B2 & Loại C & Loại D & Loại E1 & Loại E2 & Tống \\
\hline Số lượng & 1250 & 6 & 17 & 10 & 2 & 1 & 5 & 8 & 1299 \\
\hline Tỳ lẹ̣ \% & 96.2 & 0.5 & 1.3 & 0.8 & 0.2 & 0.1 & 0.4 & 0.6 & $100 \%$ \\
\hline \multicolumn{8}{|c|}{ Của chúng tôi } \\
\hline Số lượng & 570 & 55 & 64 & 10 & 6 & 0 & 14 & 1 & 720 \\
\hline Tỷ lệ \% & $79,2 \%$ & 7,6 & 8,9 & 1,4 & 0,8 & 0 & 1,9 & 0,1 & $100 \%$ \\
\hline
\end{tabular}

\section{KẾT LUẬN}

Số lượng chân răng 2 bên phải và trái khác biệt nhau không có ý nghĩa thống kê. Răng 7 trền thường có 3 chân $(91,25 \%)$, sau đấy là 2 chân $(6,94 \%), 1$ chân $(1,4 \%)$ và 4 chân $(0,4 \%)$. Số lượng 2 chân và 3 chân ở nữ $(5,1 \%$ và $49 \%)$ cao hơn nam ( $1,8 \%$ và $42 \%)$.

Chân gần ngoài răng 7 hàm trên chủ yếu có 1 ống tủy thẳng từ trên xuống (vertucci $\mathrm{I}$ ) chiếm $84,7 \%$, nữ $(85,5 \%)$ cao hơn nam $(83,8 \%)$. Sự khác nhau bên phải và trái không có ý nghĩa thống kê. Chân xa và chân trong chỉ có 1 ống tủy từ lỗ vào ống tủy đến chóp răng (loại I Vertucci)

Hình thái ống tủy chữ C chiếm $20,8 \%$ số răng 7 hàm trên nghiên cứu, trong đó hình thái $\mathrm{B} 1$ chiếm $8,9 \%$ và $A$ chiếm $7,6 \%$. Không khác biệt 2 bên phải trái, nhưng hay gặp ở nữ $(24,3 \%)$ hơn là ở nam $(16,6 \%)$.

LỜI CẢM ON. Chúng tôi xin cảm ơn bộ môn Răng Hàm Mặt - Trường Đại Học Y Dược ĐHQGHN, đã tạo điều kiện cơ sở vật chất và đối tượng nghiên cứu để hoàn thành đề tài.

\section{TÀI LIỆ THAM KHẢO}

1. Alamri, H.M., et al., Root canal morphology of maxillary second molars in a Saudi sub-population:
A cone beam computed tomography study. Saudi Dent J, 2020. 32(5): p. 250-254.

2. Mandana Naseri a, M.A.M.a., Yaser Safi b, Maryam Heidarnia c, Alireza and N.N. Akbarzadeh Baghban d, Root Canal Morphology of Maxillary Second Molars according to Age and Gender in a Selected Iranian Population A Cone-Beam Computed Tomography Evaluation. Iranian Endodontic Journal 2018, 2018. ;13(3):: p. 373-380.

3. Wolf, T.G., et al., Root canal morphology and configuration of 123 maxillary second molars by means of micro-CT. Int J Oral Sci, 2017. 9(1): p. 33-37.

4. VERTUCCI, F.J., Root canal morphology and its relationship to endodontic procedures. Endodontic Topics, 2005. 10, : p. 3-29.

5. Bansal, R., S. Hegde, and M.S. Astekar, Classification of Root Canal Configurations: A Review and a New Proposal of Nomenclature System for Root Canal Configuration. Journal of Clinical and Diagnostic Research, 2018.

6. Martins, J.N., et al., Prevalence and Characteristics of the Maxillary C-shaped Molar. J Endod, 2016. 42(3): p. 383-9.

7. Hiền, H.H.T., Đặc Điểm Hình Thái Chân Răng Và Ống Tủy Răng Cổi Lớn Thứ Nhất Và Thứ Hai Người Việt Nam . Luận án Tiến sĩ, trường Đại Học Y Dược TP Hồ Chí Minh, 2019.

8. J. DHAYANITHI, D.A.K., DR.M.P. BRUNDHA Variations in The Number of Roots and Root Canals in Maxillary Second Molars- A Review of Literature. Journal of Contemporary Issues in Business and Government, 2021. 27(02).

\section{ĐÁNH GIÁ KẾT QUẢ PHẪU THUÂTT ĐĂT ĐIÊ̂N CỰC KÍCH THÍCH NÃO SÂU ĐIỀU TRI BỆNH LÝ PARKINSON VỒ CĂN TẠI BỆNH VIỆN VIỆT ĐỨC}

\section{TÓM TẮT}

Mục tiêu: Mô tả kết qủa 10 trường hợp bệnh nhân Parkinson vô căn được điều trị bằng phẫu thuật kích thích não sâu tại Bệnh viện Việt Đức từ tháng 1 năm 2016 đến tháng 5 năm 2020. Đối tượng và

*Bệnh viện Việt Đức

Chiu trách nhiệm chính: Trân Đình Văn

Email: tranvanpttk@gmail.com

Ngày nhận bài: 12.3.2021

Ngày phản biên khoa học: 11.5 .2021

Ngày duyệt bài: 18.5.2021
Trần Đình Văn*, Đồng Văn Hệ*, Nguyễn Anh Tuấn*, Ngô Thị Huyền*, Nguyễn Mạnh Tiến*

phương pháp nghiên cứu: mô tả tiến cứu, theo dõi dọc tất cả các trường hợp được chẩn đoán Parkinson vổ căn và được phẫu thuật kích thích não sâu tại Bệnh viên Viêt Đức. Kết quả: nam giới chiếm chủ yếu (70\%), tuổi trung bình khi phẫu thuật là 60 tuổi, triệu chứng lâm sàng điển hình là rối loạn vận động, thăm dò điện sinh lý trong mổ nhận diện bước sóng của STN, kết quả cải thiên vận động qua thang điểm UPDRS đánh giá sau mổ 3 tháng -6 tháng -12 tháng đều cho thây cải thiện tốt và ổn định các triêuu chứng rối loạn vận động, giảm 25 - 50\% liều lượng levodopa, không gặp biến chứng đặc biệt nào sau mố.

Tư khoá: kích thích não sâu (deep brain 